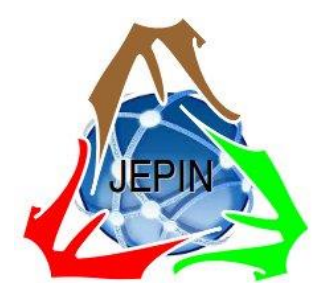

\title{
Information Retrieval pada Pencarian Menu Balita Menggunakan Dice Coefficient
}

\author{
Arfiani Nur Khusna ${ }^{\# 1}$, Luthvi Rizkawati ${ }^{* 2}$

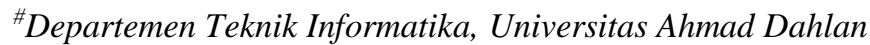 \\ Jl. Ahmad Yani (Ring Road Selatan), Kragilan, Tamanan, Banguntapan, Bantul, Yogyakarta \\ ${ }^{1}$ arfiani.khusna@tif.uad.ac.id \\ *Departemen Teknik Informatika, Universitas Ahmad Dahlan \\ Jl. Ahmad Yani (Ring Road Selatan), Kragilan, Tamanan, Banguntapan, Bantul, Yogyakarta
}

2luthvi29@gmail.com

\begin{abstract}
Abstrak - Masalah gizi menjadi salah satu faktor penyebab kesakitan dan penyebab gangguan tumbuh kembang pada balita diseluruh dunia, $75 \%$ responden kesulitan menemukan informasi tentang pencarian menu makanan yang tepat untuk balita berdasarkan bahan makanan yang tersedia sehingga menjadi salah satu faktor penyebab gizi buruk balita. Penelitian bertujuan untuk membantu pengguna menemukan informasi dalam mencari menu makanan balita berdasarkan bahan-bahan yang tersedia. Pencarian menggunakan information retrieval dengan metode Dice Coefficient untuk menghitung tingkat kesamaan antar dua buah objek dengan cara mengalikan dua jumlah nilai irisan antara dokumen menu dan query, kemudian membaginya dengan jumlah nilai dokumen menu dengan nilai query. Hasil pengujian precision 0,23 menunjukkan bahwa akurasi antara kata kunci dengan dokumen menu hasil pencarian rendah, sedangkan hasil DCG 0.98 menunjukkan peringkat dokumen menu berdasarkan posisinya sesuai dengan kata kuncinya. Pengujian sistem menggunakan user testing, hasil pengujian menunjukkan bahwa 27 dari 30 pengguna berpendapat setuju dalam kemudahan dan manfaat sistem untuk mengatur menu makanan yang tepat bagi balita sesuai bahan yang tersedia.
\end{abstract}

Kata kunci - Information Retrieval, Dice Coefficient, Menu Balita

\section{Pendahuluan}

Masalah gizi menjadi salah satu faktor penyebab kesakitan dan penyebab gangguan tumbuh kembang pada balita diseluruh dunia. Gangguan tumbuh kembang balita usia 6-24 bulan di Indonesia adalah rendahnya mutu makanan yang dikonsumsi balita dan ketidaksesuaian pola asuh yang diberikan sehingga beberapa zat gizi tidak dapat mencukupi kebutuhan energi dan zat mikro terutama zat besi $(\mathrm{Fe})$ dan seng $(\mathrm{Zn})[1]$.

Balita dengan pengetahuan gizi ibu yang kurang memiliki hubungan yang bermakna dengan kasus balita gizi kurang. Balita yang tingkat pengetahuan gizi ibunya kurang, berisiko mengalami gizi buruk 5,091 kali lebih besar daripada balita yang ibunya memiliki tingkat pengetahuan baik [2]. Menu balita merupakan makanan atau minuman yang mengandung zat gizi, diberikan kepada bayi atau anak usia 6-24 bulan guna memenuhi kebutuhan gizi selain dari ASI, diperlukan untuk mengisi kesenjangan antara total kebutuhan nutrisi bayi dengan jumlah nutrisi yang didapatkan dari ASI saja, karena jika kesenjangan tersebut tidak dipenuhi maka pertumbuhan bayi akan terhambat atau terhenti. Beberapa faktor yang harus diperhatikan dalam pemberian menu balita yaitu faktor usia, frekuensi, jumlah pemberian, tekstur, keberagaman makanan, reaksi keaktifan bayi terhadap makanan dan higienis. [3]

Berdasarkan hasil kuisioner mengenai pengetahuan terhadap pemberian makanan balita dan disebarkan kepada 50 responden yang mempunyai balita, terdapat $75 \%$ responden mempunyai bahan makanan yang siap untuk diolah namun kesulitan menemukan informasi tentang pencarian menu makanan yang bernilai gizi tinggi untuk disajikan pada balita sesuai dengan usianya berdasarkan bahan yang sudah ada [4].

Perkembangan teknologi informasi sangat berperan penting dalam berbagai sektor kehidupan manusia. Khususnya pada bidang kesehatan, masih terdapat ibu yang belum sadar akan kebutuhan menu makanan yang sehat dan tepat sesuai dengan usia balita, baik dari segi bahan makanan maupun nilai nutirisi gizi atau yang terkandung dalam menu makanan tersebut. Saat ini banyak media informasi online seperti website ataupun aplikasi android yang menyajikan beragam menu makanan untuk balita, namun media-media tersebut belum dapat membantu ibu dalam mencari menu makanan berdasarkan bahan makanan lokal yang sesuai dengan usia balita.

Information Retrieval atau Temu Balik Informasi merupakan bagian dari computer science tentang pengambilan informasi dari dokumen-dokumen yang didasarkan pada isi dan konteks dari dokumen-dokumen itu sendiri. Information Retrieval adalah suatu sistem yang 
mampu melakukan penyimpanan, pencarian, dan pemeliharaan informasi. Informasi dalam konteks ini dapat terdiri dari teks (termasuk data numerik dan tanggal), gambar, audio, video, dan objek multimedia lainnya [5].

Information Retrieval menerapkan berbagai macam algoritma similarity untuk mencari kesamaan antar dokumen dan query, salah satunya yaitu Dice Similarity [6][7]. Dice Coefficient atau Dice Similarity adalah algoritma yang digunakan untuk menghitung tingkat kesamaan (similarity) antar dua buah objek dengan cara mengalikan 2 jumlah nilai irisan antara dokumen dan query, kemudian membaginya dengan jumlah nilai dokumen dengan nilai query. Dice Coefficient tidak memperhatikan berapa kali suatu term muncul di dalam suatu dokumen [8][9].

Secara teknis, tujuan information retrieval adalah mencocokan (matching) term atau istilah yang dibangun (query) dengan term atau indeks yang ada dalam dokumen, sehingga dengan kecocokan tersebut maka dokumendokumen yang relevan akan terambil (retrived) dari database. Terambilnya dokumen berdasarkan permintaan pengguna dengan harapan bahwa content atau isi dari dokumen yang terambil tersebut relevan dengan kebutuhan informasi pencari informasi.

Preprocessing merupakan tahap yang penting dalam pemrosesan teks pada pengambilan informasi untuk memperoleh fitur yang akan diproses pada tahap selanjutnya. Tugas pokok pada tahap ini adalah pembangunan indeks dari koleksi dokumen (Indexing). Indexing adalah proses membangun representasi suatu dokumen dengan memberikan suatu pengenal pada itemitem teks. Kualitas indeks mempengaruhi efektifitas dan efisiensi sistem information retrieval. Elemen dari indexing adalah fitur (keyword, term, dan istilah) yang dapat diperoleh dari ekstraksi teks suatu dokumen yang akan dimodelkan. Indeks dokumen adalah himpunan term yang menunjukkan isi topik yang dikandung oleh dokumen. Indeks akan membedakan antara satu dokumen dengan satu dokumen lain yang berada didalam koleksi [10].

Pembobotan kata sangat berpengaruh dalam menentukan kemiripan antara dokumen dengan query. Apabila bobot tiap kata dapat ditentukan dengan tepat, diharapkan hasil perhitungan kemiripan teks akan menghasilkan perangkingan dokumen yang baik. Faktor yang memegang peranan penting dalam pembobotan kata yaitu Term Frequency (tf). Faktor ini menyatakan banyaknya kemunculan suatu kata dalam suatu dokumen. Semakin sering suatu kata muncul dalam sebuah dokumen, berarti semakin penting kata tersebut [11].

Metode Dice's Similarity Coefficient atau biasa dikenal dengan nama Sorensen-Dice Coefficient digunakan dalam perhitungan kemiripan dokumen. Rumus yang digunakan, yaitu: [12]

$$
\operatorname{Dice}(D, Q)=\frac{2|D \cap Q|}{|D|+|Q|}
$$

Dimana:

$\mathrm{D}(\mathrm{D}, \mathrm{Q})$ : nilai similaritas antara set $\mathrm{D}$ dan set $\mathrm{Q}$

$|\mathrm{D} \cap \mathrm{Q}|$ : banyaknya elemen yang sama antara set $\mathrm{D}$ dan set Q

|D| : banyak elemen yang terdapat pada set $\mathrm{D}$

Q $\quad$ : banyak elemen yang terdapat pada set $\mathrm{Q}$

Pengujian akurasi menggunakan precision dengan rasio dokumen relevan yang berhasil ditemukembalikan dari seluruh dokumen yang ditemukembalikan. Nilai tertinggi precision adalah 1 atau $100 \%$ yang berarti seluruh dokumen yang ditemukan adalah relevan, precision didefinisikan sebagai berikut: [13]

Precision $(P)=\frac{\text { Jumlah dokumen relevan yang terambil }}{\text { Jumlah dokumen terambil dalampencarian }}$

Discounted Cumulative Gain (DCG) merupakan metode untuk mengukur kualitas peringkat dokumen berdasarkan posisinya dalam daftar hasil. DCG pada posisi p peringkat tertentu didefinisikan sebagai berikut: [14]

$D C G p=\sum_{i=1}^{p} \frac{r e l i}{\log _{2}(i+1)}$

Dimana:

$\operatorname{rel}(i)=\left\{\begin{array}{c}1, \text { jika dokumen ke i relevant } \\ 0, \text { jika dokumen ke } i \text { irrelevant }\end{array}\right.$

Kemudian akan menghitung Ideal Discounted Cumulative Gain yang mewakili daftar dokumen yang relevan di dalam database dan disesuaikan dengan peringkat dokumen yang diharapkan. Pengukuran DCG yang dinormalisasi, mengaitkan nilai DCG yang ideal, untuk setiap posisi peringkat $p$, berdasarkan skor yang diharapkan pada posisi. IDCG didefinisikan sebagai berikut: [15]

$$
\text { IDCGp }=\sum_{i=1}^{R E L} \frac{\text { rel } i}{\log _{2}(i+1)}
$$

Menghitung nilai Normalized Discounted Cumulative Gain (nDCG) untuk mendapatkan ukuran kinerja peringkat rata-rata algoritma yang diterapkan pada mesin pencari. Perlu diperhatikan bahwa dalam algoritma peringkat sempurna yang menghasilkan nDCG 1, ukuran DCG yang dinormalisasi mendekati 1 hanya jika DCG pada setiap posisi dekat dengan IDCD (yang diharapkan) sesuai. nDCG memperhitungkan secara langsung hubungan skorperingkat yang diharapkan ketika menilai efektivitas pengambilan, nDCG didefinisikan sebagai berikut:

$n D C G=\frac{D C G p}{I D C G p}$ 


\section{Metodelogi Penelitian}

\section{A. Tahap Pengembangan Sistem.}

Tahapan pengembangan sistem dalam pengambilan informasi seperti yang telah digambarkan pada gambar 1 . Berikut tahapan dalam pengembangan sistem :

1. Collect data, data yang dikumpulkan adalah menu MPASI untuk balita berusia 6-24 bulan dalam bentuk file excel yang didapat dari open source internet.

2. Preprocessing text, adalah proses untuk menghilangkan tanda baca, angka dan merubah semua huruf menjadi huruf kecil serta menjadi kata dasar pada data bahan baku dalam menu makanan balita yang terdiri dari tokenize, stopword dan stemming.

3. Proses term weighting. adalah proses pembobotan kata berdasarkan kemunculan term pada dokumen dari bahan baku dalam menu makanan balita.

4. Proses hitung nilai similarity, adalah untuk menghitung nilai kemiripan dokumen antara dua objek berdasarkan query yang ingin dicari.

5. Ranking dokumen, adalah hasil data menu MPASI berdasarkan query yang dicari. Urutan data yang muncul paling atas adalah data dengan skor paling tinggi.

\section{B. Perancangan Basis Data}

Basis data yang digunakan dalam program ini adalah data set file excel. Perancangan basis data digunakan untuk menentukan data apa saja yang akan masuk ke dalam basis data (database) dan digunakan untuk mendukung rancangan sistem, diantaranya:

1. Data menu pada tabel 1 , untuk menyimpan file data set yang telah di upload.

TABEL I

DATABASE MENU

\begin{tabular}{|l|l|}
\hline \multicolumn{1}{|c|}{ Key } & \multicolumn{1}{c|}{ Type Values } \\
\hline Id & Objectld \\
\hline Nama & String \\
\hline Bahan & String \\
\hline Resep & String \\
\hline Usia & String \\
\hline
\end{tabular}

2. Data bahan pada tabel 2, untuk menyimpan setiap dokumen bahan yang mengalami preprocessing.

TABEL II

DATABASE MENU

\begin{tabular}{|c|l|}
\hline Key & \multicolumn{1}{|c|}{ Type Values } \\
\hline Id & ObjectId \\
\hline Bahan & String \\
\hline
\end{tabular}

\section{Pengujian}

Tahap pengujian sistem terhadap metode Discounted Comulative Gain menggunakan 2 metode pengujian, yaitu metode Precision untuk mengetahui kesesuaian hasil pencarian sistem antara query dan dokumen, serta menggunakan metode Discounted Comulative Gain untuk mengukur kualitas hasil rangking dokumen sehingga dapat diketahui efektivitas algoritma yang diterapkan pada mesin pencarian. Selain 2 metode pengujian, terdapat pengujian kepada pengguna untuk mengukur manfaat dan kemudahan sistem kepada pengguna menggunakan user testing.

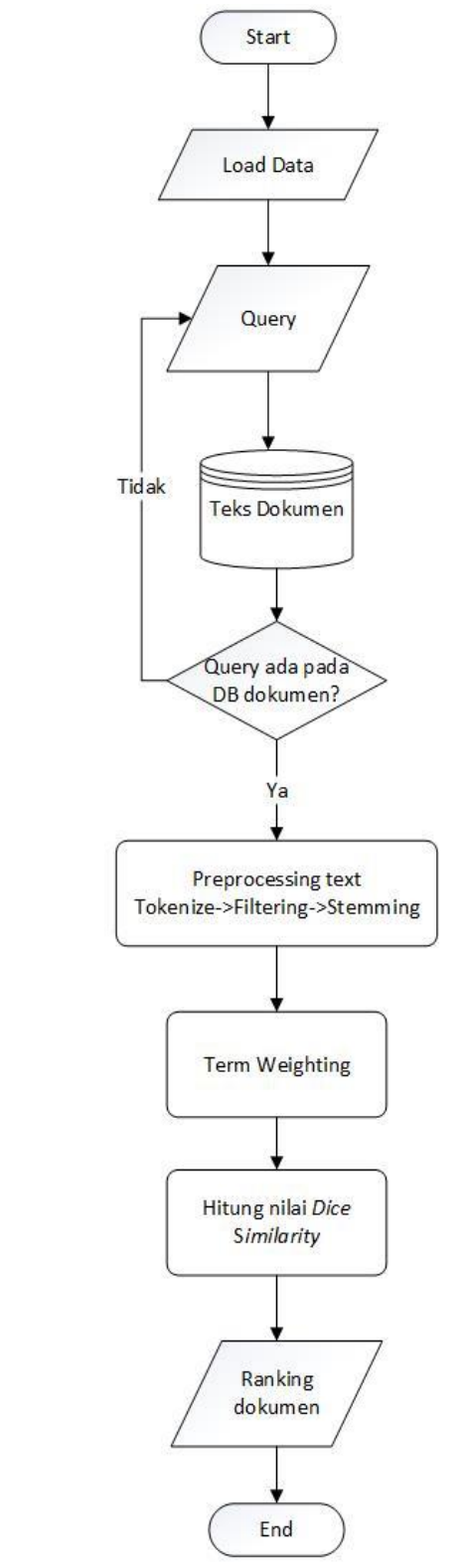

Gambar. 1 Tahapan pengembangan sistem

\section{HASIL DAN PEMBAHASAN}

Data yang digunakan dalam penelitian ini adalah data menu makanan untuk balita yang berusia 6-24 bulan. Data didapat dari website www.ayahbunda.co.id yang disimpan dalam bentuk file excel dan terdapat sebuah tabel dengan 280 baris dan 4 kolom (atribut), yaitu: nama, bahan, resep, dan usia. Fokus pada penelitian ini yaitu melakukan proses pencarian dan menemukan dokumen relevan berdasarkan bahan baku menu makanan balita. Tahapan-tahapan perhitungan Dice Coefficient yaitu: 
Query (Q) : Dada ayam brokoli

Dokumen 1 : 50 gram ayam, 50 gram brokoli, $100 \mathrm{ml}$ kaldu ayam.

Dokumen 2 : 50 gram brokoli, 50 gram dada ayam, 50 gram kentang.

Dokumen 3 : 25 gram brokoli, 200 gram kentang, 100 gram tahu.

\section{A. Tokenize}

Proses dilakukan untuk menghilangkan tanda baca pada dokumen sehingga menghasilkan kata-kata yang berdiri sendiri, terdapat pada tabel 3.

TABEL III

PROSES TOKENISASI

\begin{tabular}{|c|c|c|c|}
\hline No & \multicolumn{3}{|c|}{ Term yang mewakili dokumen } \\
\hline & D1 & D2 & D3 \\
\hline 1 & 50 & 50 & 25 \\
\hline 2 & gram & gram & gram \\
\hline 3 & ayam & brokoli & brokoli \\
\hline 4 & 50 & 50 & 200 \\
\hline 5 & gram & gram & gram \\
\hline 6 & brokoli & dada & kentang \\
\hline 7 & 100 & ayam & 100 \\
\hline 8 & $\mathrm{ml}$ & 50 & gram \\
\hline 9 & kaldu & gram & tahu \\
\hline 10 & ayam & kentang & \\
\hline
\end{tabular}

\section{B. Stopword}

Proses bertujuan mengambil kata-kata penting dari hasil tokenisasi yang terdapat pada tabel 4 .

TABEL IV

PROSES STOPWORD

\begin{tabular}{|c|l|l|l|}
\hline No & \multicolumn{3}{|c|}{ Term yang mewakili dokumen } \\
& \multicolumn{1}{|c|}{ D1 } & \multicolumn{1}{c|}{ D2 } & \multicolumn{1}{c|}{ D3 } \\
\hline & ayam & brokoli & brokoli \\
\hline 1 & brokoli & dada & kentang \\
\hline 2 & ayam & tahu \\
\hline 3 & kaldu & yam & \\
\hline 4 & ayam & kentang & \multicolumn{2}{|c|}{} \\
\hline
\end{tabular}

\section{Stemming}

Proses bertujuan mengembalikan term ke kata dasar dengan cara menghapus imbuhan yang berada di depan maupun di belakang kata, terdapat pada tabel 5 .

\section{Term Weighting}

Tahap untuk memperhatikan apakah suatu kata (token) ada atau tidak pada dokumen. Akan bernilai 0 apabila term tidak ada pada sebuah dokumen, dan bernilai 1 apabila term tersebut ada dalam dokumen, terdapat pada tabel 6 .

TABEL V

PROSES STEMMING

\begin{tabular}{|c|l|l|l|}
\hline No & \multicolumn{3}{|c|}{ Term yang mewakili dokumen } \\
\hline & \multicolumn{1}{|c|}{ D1 } & \multicolumn{1}{c|}{ D2 } & D3 \\
\hline 1 & ayam & brokoli & brokoli \\
\hline 2 & brokoli & dada & kentang \\
\hline
\end{tabular}

\begin{tabular}{|l|l|l|l|}
\hline 3 & kaldu & ayam & tahu \\
\hline 4 & ayam & kentang & \\
\hline \multicolumn{4}{|c|}{ TABEL VI } \\
PROSES TERM WEIGHTING
\end{tabular}

\begin{tabular}{|l|c|c|c|c|}
\hline \multirow{2}{*}{ Term } & \multicolumn{4}{c|}{ TF } \\
\cline { 2 - 5 } & $\boldsymbol{Q}$ & D1 & D2 & D3 \\
\hline Ayam & 1 & 2 & 1 & 0 \\
\hline Brokoli & 1 & 1 & 1 & 1 \\
\hline Kaldu & 0 & 1 & 0 & 0 \\
\hline Dada & 1 & 0 & 1 & 0 \\
\hline Kentang & 0 & 0 & 1 & 1 \\
\hline Tahu & 0 & 0 & 0 & 1 \\
\hline Jumlah & $\mathbf{3}$ & $\mathbf{3}$ & $\mathbf{4}$ & $\mathbf{3}$ \\
\hline$\left|\mathbf{D}_{\mathbf{n}} \cap \mathbf{Q}\right|$ & - & $\mathbf{2}$ & $\mathbf{3}$ & $\mathbf{1}$ \\
\hline
\end{tabular}

\section{E. Dice Coefficient}

Berikut perhitungan menggunakan metode Dice's Coefficient:

$$
\begin{aligned}
& |\mathbf{D} 1 \cap \mathbf{Q}|=\{\text { ayam, brokoli }\}, \mathrm{n}=2 \\
& \text { Dice }(D 1, Q)=\frac{2|D 1 \cap Q|}{|D 1|+|Q|}=\frac{2.2}{3+3}=0,67
\end{aligned}
$$

$|\mathbf{D} 2 \cap \mathbf{Q}|=\{$ ayam, brokoli, dada $\}, \mathrm{n}=3$

$$
\begin{aligned}
|\mathbf{D 3} \cap \mathbf{Q}|=\{\text { brokoli }\}, \mathrm{n} & =1 \\
\text { Dice }(D 3, Q) & =\frac{2|D 3 \cap Q|}{|D 3|+|Q|}=\frac{2.1}{3+3}=0,33
\end{aligned}
$$

Berdasarkan hasil perhitungan maka akan dilakukan perangkingan pada masing-masing dokumen berdasarkan nilai tertinggi hingga terendah yaitu D2, D1 dan D3 sehingga hasil dokumen yang relevan terhadap query yang diinputkan pengguna ialah dokumen D2 yang menghasilkan skor 0,86 .

\section{F. Implementasi}

Load data sebagai tampilan untuk upload dataset excel yang digunakan sebagai objek terdapat pada gambar 2 .

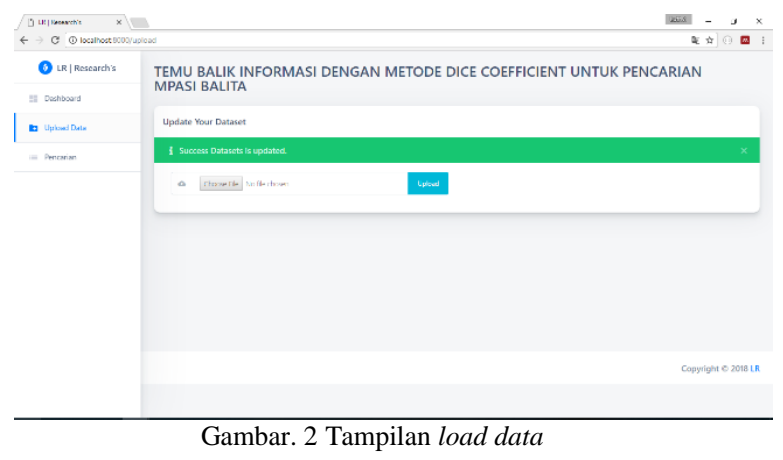


Searching sebagai mesin pencarian untuk menemukan dokumen relevan berdasarkan query yang telah diinputkan pengguna. Pada halaman ini akan ditampilkan 10 list rekomendasi menu makanan balita sesuai usia balita berdasarkan hasil perhitungan skor terbesar hingga terkecil yang menerapkan metode Dice Coefficient terdapat pada gambar 3.

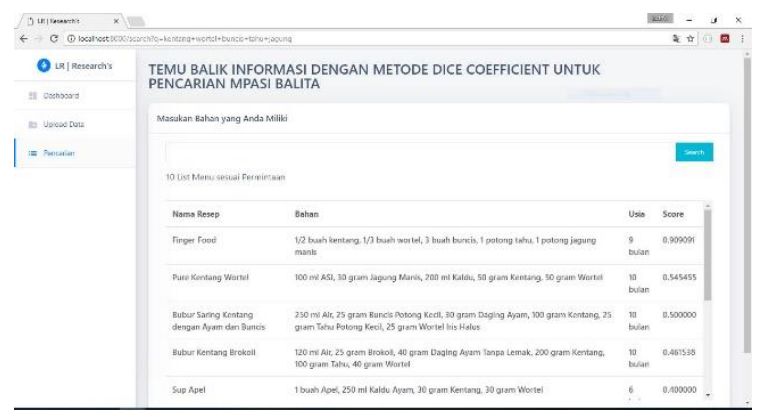

Gambar. 3 Tampilan pencarian dan perhitungan nilai dice coefficient

TABEL VIII

HASIL PERHITUNGAN DisCounted CUMULATIVE GAIN

\begin{tabular}{|c|c|c|c|c|}
\hline No & Query & DCGp & IDCGp & $n D C G$ \\
\hline 1. & Kentang & 4.549 & 4.549 & 1 \\
\hline 2. & Apel & 4.549 & 4.549 & 1 \\
\hline 3. & Wortel & 4.549 & 4.549 & 1 \\
\hline 4. & Jagung & 4.549 & 4.549 & 1 \\
\hline 5. & Stroberi & 3.642 & 3.642 & 1 \\
\hline 6. & Edamame makaroni & 1 & 1 & 1 \\
\hline 7. & Salmon kentang & 1 & 1 & 1 \\
\hline 8. & Ubi bayam & 2.132 & 2.132 & 1 \\
\hline 9. & Tahu Tempe & 1 & 1 & 1 \\
\hline 10. & Brokoli wortel & 3.027 & 3.308 & 0.914 \\
\hline 11. & Wortel kentang ayam & 2.752 & 2.951 & 0.932 \\
\hline 12. & Kacang polong keju & 1.865 & 2.563 & 0.727 \\
\hline 13. & Bayam ikan makaroni & 1.632 & 1.631 & 1 \\
\hline 14. & Jeruk mangga melon & 1 & 1 & 1 \\
\hline 15. & Sawi buncis telur & 1 & 1 & 1 \\
\hline 16. & $\begin{array}{l}\text { Jagung tahu kentang } \\
\text { wortel }\end{array}$ & 1 & 1 & 1 \\
\hline 17. & Nasi patin buncis kaldu & 1 & 1 & 1 \\
\hline 18. & $\begin{array}{l}\text { Pisang ambon keju } \\
\text { cheddar }\end{array}$ & 2.132 & 2.132 & 1 \\
\hline 19. & $\begin{array}{l}\text { Beras merah kacang } \\
\text { wortel }\end{array}$ & 1 & 1 & 1 \\
\hline 20. & Beras tempe ayam teri & 1 & 1 & 1 \\
\hline 21. & $\begin{array}{l}\text { Hati ayam terong bayam } \\
\text { margarin }\end{array}$ & 1.632 & 1.632 & 1 \\
\hline 22. & $\begin{array}{l}\text { Kentang wortel buncis } \\
\text { tahu jagung }\end{array}$ & 1 & 1 & 1 \\
\hline 23. & $\begin{array}{l}\text { Pir pulm susu formula } \\
\text { cair }\end{array}$ & 1 & 1 & 1 \\
\hline 24. & $\begin{array}{l}\text { Roti tawar gandum } \\
\text { pisang keju }\end{array}$ & 1 & 1 & 1 \\
\hline 25. & $\begin{array}{l}\text { Daging sapi wortel } \\
\text { havermut susu }\end{array}$ & 1 & 1 & 1 \\
\hline & \multicolumn{3}{|c|}{ Rata-rata } & $\begin{array}{l}0.982 \cong \\
0.98\end{array}$ \\
\hline
\end{tabular}

TABEL VII

HASIL PERHITUNGAN PRECISION

\begin{tabular}{|c|c|c|c|c|c|}
\hline No & Query & Term & $R a$ & $R t$ & Precision \\
\hline 1. & Kentang & 1 & 31 & 31 & 1 \\
\hline 2. & Apel & 1 & 14 & 14 & 1 \\
\hline 3. & Wortel & 1 & 66 & 66 & 1 \\
\hline 4. & Jagung & 1 & 29 & 29 & 1 \\
\hline 5. & Stroberi & 1 & 7 & 7 & 1 \\
\hline 6. & $\begin{array}{l}\text { Edamame } \\
\text { makaroni }\end{array}$ & 2 & 1 & 10 & 0.1 \\
\hline 7. & Salmon kentang & 2 & 1 & 40 & 0.025 \\
\hline 8. & Ubi bayam & 2 & 3 & 44 & 0.068 \\
\hline 9. & Tahu Tempe & 2 & 1 & 32 & 0.031 \\
\hline 10. & Brokoli wortel & 2 & 8 & 82 & 0.098 \\
\hline 11. & $\begin{array}{l}\text { Wortel kentang } \\
\text { ayam }\end{array}$ & 3 & 5 & 126 & 0.04 \\
\hline 12. & $\begin{array}{l}\text { Kacang polong } \\
\text { keju }\end{array}$ & 3 & 5 & 69 & 0.072 \\
\hline 13. & $\begin{array}{l}\text { Bayam ikan } \\
\text { makaroni }\end{array}$ & 3 & 2 & 62 & 0.032 \\
\hline 14. & $\begin{array}{l}\text { Jeruk mangga } \\
\text { melon }\end{array}$ & 3 & 1 & 40 & 0.025 \\
\hline 15. & Sawi buncis telur & 3 & 1 & 45 & 0.022 \\
\hline 16. & $\begin{array}{l}\text { Jagung tahu } \\
\text { kentang wortel }\end{array}$ & 4 & 1 & 106 & 0.009 \\
\hline 17. & $\begin{array}{l}\text { Nasi patin buncis } \\
\text { kaldu }\end{array}$ & 4 & 1 & 85 & 0.012 \\
\hline 18. & $\begin{array}{l}\text { Pisang ambon } \\
\text { keju cheddar }\end{array}$ & 4 & 3 & 51 & 0.059 \\
\hline 19. & $\begin{array}{l}\text { Beras merah } \\
\text { kacang wortel }\end{array}$ & 4 & 1 & 150 & 0.007 \\
\hline 20. & $\begin{array}{l}\text { Beras tempe ayam } \\
\text { teri }\end{array}$ & 4 & 1 & 121 & 0.008 \\
\hline 21. & $\begin{array}{l}\text { Hati ayam terong } \\
\text { bayam margarin }\end{array}$ & 5 & 2 & 107 & 0.019 \\
\hline 22. & $\begin{array}{l}\text { Kentang wortel } \\
\text { buncis tahu } \\
\text { jagung }\end{array}$ & 5 & 1 & 118 & 0.008 \\
\hline 23. & $\begin{array}{l}\text { Pir pulm susu } \\
\text { formula cair }\end{array}$ & 5 & 1 & 65 & 0.015 \\
\hline 24. & $\begin{array}{l}\text { Roti tawar } \\
\text { gandum pisang } \\
\text { keju }\end{array}$ & 5 & 1 & 83 & 0.012 \\
\hline 25. & $\begin{array}{l}\text { Daging sapi } \\
\text { wortel havermut } \\
\text { susu }\end{array}$ & 5 & 1 & 158 & 0.006 \\
\hline & & \multicolumn{3}{|c|}{ Rata-rata } & $0.227 \cong 0.23$ \\
\hline
\end{tabular}

\section{G. Pengujian}

Pada pengujian Precision akan menggunakan data sebanyak 280 dokumen MPASI yang terdapat dalam database. Pengujian pada sistem dengan menggunakan 25 query yang berbeda di setiap pengujian, hasil pengujian menunjukkan bahwa nilai precision menunjukkan rata-rata bernilai 0.23 . Hal ini menunjukkan bahwa masih terdapat dokumen lain selain dokumen relevan yang ikut ditemukan oleh sistem sehingga membuktikan bahwa keakurasian antara query yang dimasukkan dengan dokumen hasil pencarian masih kurang relevan dimana kondisi ideal precision adalah bernilai 1. Pada tabel 7 menunjukkan hasil precision menggunakan persamaan 2 , dengan $\mathrm{Ra}=\mathrm{Jumlah}$ dokumen relevan yang terambil dan $\mathrm{Rt}=$ Jumlah dokumen yang terambil dalam pencarian. 
Hasil pengujian pada tabel 8 merupakan perhitungan pengujian Discounted Cumulative Gain menggunakan data uji sebanyak 25 query. Langkah pertama menghitung nilai DCGp terlebih dahulu menggunakan persamaan 3, selanjutnya menghitung nilai IDCGp menggunakan persamaan 4 dan menghitung nilai $n D C G$ menggunakan persamaan 5. Hasil menunjukkan bahwa kinerja peringkat dokumen rata-rata algoritma yang diterapkan pada mesin pencari dinilai efektif karena menghasilkan nilai 0,98 bahwa kualitas peringkat dokumen berada pada posisi atas rangking dokumen dalam hasil pencarian dan hasil tersebut sesuai dengan skor similarity.

Pengujian user testing untuk pernyataan manfaat dan kemudahan sistem terhadap pengguna. Hasil pengujian pengguna menjawab sangat setuju 27 dan tidak setuju 3 dari 30 pengguna. Berdasarkan hasil user testing dapat diinterpretasikan bahwa dengan menggunakan sistem, pengguna dapat menemukan informasi dalam pencarian menu makanan balita dengan bahan yang telah tersedia.

\section{KESIMPULAN}

Berdasarkan hasil penelitian dapat disimpulkan bahwa:

1. Information retrieval dengan metode Dice Coefficient untuk pencarian menu makanan balita mampu melakukan pencarian sesuai dengan kata kunci yang dicari.

2. Pengujian precision menghasilkan nilai 0.006 yang menunjukkan bahwa masih terdapat dokumen lain selain dokumen relevan yang ikut ditemukan oleh sistem dan dokumen yang diharapkan dapat ditemukan sedikit.

3. Nilai rata-rata precision yaitu 0.23 yang membuktikan bahwa keakurasian antara query yang dimasukkan dengan dokumen hasil pencarian masih kurang relevan dimana kondisi ideal precision adalah 1.

4. Segi kualitas peringkat dokumen, kinerja peringkat dokumen rata-rata algoritma yang diterapkan pada mesin pencari dinilai efektif karena menghasilkan nilai 0.98 sehingga metode Dice Coefficient merupakan salah satu metode yang dinilai efektif apabila diterapkan pada mesin pencari.

5. Pengujian user testing terhadap pengguna, menunjukkan bahwa 27 dari 30 pengguna berpendapat setuju dalam kemudahan dan manfaat sistem untuk menemukan informasi dalam pencarian menu makanan bagi balita sesuai bahan yang tersedia.

\section{REFERENSI}

[1] S. Damayanti, Hubungan Pola Pemberian Makanan Pendamping ASI dengan Status Gizi Balita Usia 6-24 Bulan pada Salah Satu Desa di Wilayah Lampung Timur. Keperawatan, XII(2), 257-263, 2016.

[2] L. Mufida, T. D. Widyaningsih \& J. M. Maligan, Prinsip Dasar Makanan Pendamping Air Susu Ibu ( MP-ASI ) untuk Bayi 6 - 24 Bulan: Kajian Pustaka. Basic Principles of Complementary Feeding for Infant 6 - 24 Months : A Review. Jurnal Pangan Dan Agroindustri, 3(4), 1646-1651, 2015.

[3] L. Sofiana \& A. N. Khusna, Health Counseling to Enhance Maternal Knowledge about Nutrition in Toddlers. International Journal of Healthcare Research. 1(2), 59-62, 2018

[4] A. N. Khusna, Perancangan Sistem Informasi Panduan Gizi Makanan Balita. Seminar Nasional Informatika Medis (SNIMed), 3-8, 2018.

[5] N. Hasanah, Sistem Pencarian Skripsi Berbasis Information Retrieval di FASTIKOM UNSIQ. Jurnal PPKM, 1(1), 105-113, 2017.

[6] D. Susan, C. Edward, J. J. Cadiz , J. Gavin, S. Raman, D. C. Robbins, Stuff I've Seen: A System for Personal Information Retrieval and Re-Use, ACM SIGIR Forum, v.49 n.2, December 2015.

[7] R. T. Wahyuni, Penerapan Algoritma Cosine Similarity dan Pembobotan TF-IDF pada Sistem Klasifikasi Dokumen Skripsi. Jurnal Teknik Elektro Universitas Negeri Semarang, 9(1), 18-23, 2017.

[8] F. Amin \& E. Winarno, Rancang Bangun Sistem Temu Kembali Informasi ( Information Retrieval System ) Dokumen Berbahasa Jawa menggunakan Metode DICE Similarity. Jurnal Teknologi Informasi DINAMIK, 21(2), 99-106, 2016.

[9] K. Rinartha, Simple Query Suggestion untuk Pencarian Artikel Menggunakan Jaccard Similarity, 3(1), 30-34, 2017.

[10] Kurniawati. Term Weighting Berbasis Indeks Kelas Menggunakan Metode TF.IDF.ICSאF Untuk Perangkingan Dokumen Al-Qur'an. Universitas Islam Negeri Maulana Malik Ibrahim Malang (Skripsi), 2016.

[11] A. N. Khusna, and I. Agustina, Implementation of Information Retrieval Using Tf-Idf Weighting Method On Detik.Com's Website, 12th International Conference on Telecommunication Systems, Services, and Applications (TSSA), Yogyakarta, Indonesia, pp. 1-4, 2018.

[12] E. A. Lisangan, Implementasi n-Gram Technique Dalam Deteksi Plagiarism Pada Tugas Mahasiswa. TEMATIKA, Journal of Informatics and Information Systems, 1(2), 24-30, 2013.

[13] J. C. Krzysztof, Data Mining A Knowledge Discovery Approach. Spingers. 2007.

[14] V. Thada, Comparison of Jaccard , Dice , Cosine Similarity Coefficient To Find Best Fitness Value for Web Retrieved Documents Using Genetic Algorithm. International Journal of Innovations in Engineering and Technology, 2(4), 202-205, 2013.

[15] R. Jayashree \& A. Christy: Improving the enhanced recommended system using Bayesian approximation method and normalized discounted cumulative gain. Procedia Comput. Sci. 50, 216-222, 2015 . 